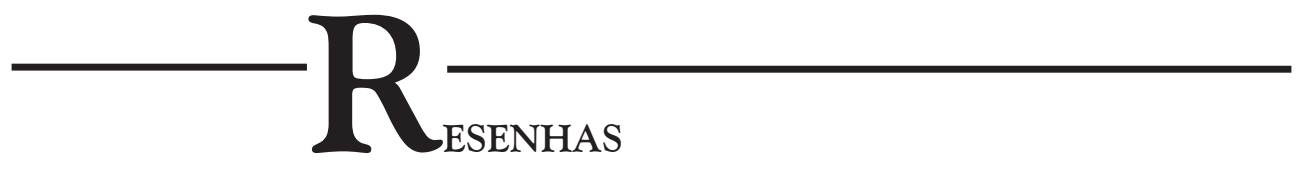

LARSEN, Timothy. The Slain God. Anthropologists $\mathcal{E}$ the Christian Faith. Oxford: Oxford University Press, 2014, 256 pp.

\title{
UMA PEREgrinAÇÃo PElA Antropologia BritÂnicA
}

\author{
Eduardo Dullo \\ Universidade de São Paulo - São Paulo \\ São Paulo - Brasil
}

A impressionante pesquisa de Timothy Larsen faz parte de um seleto grupo capaz de modificar ou aprofundar alguns entendimentos que diversos antropólogos possuem a respeito de um tema crucial da disciplina: Qual a importância da crença do pesquisador na produção de seus trabalhos? Faz alguma diferença um pesquisador escrever sobre religião num contexto de expansão do pensamento secularista na Inglaterra vitoriana? Ou qual o impacto de uma educação católica desde a infância numa jovem que virá a escrever sobre rituais? Ou ainda, o que pode ter ocasionado mudanças de perspectivas e conversões como as de Evans-Pritchard ou do casal Turner ao catolicismo? E qual diferença isso fez na obra deles? 
Ainda que o autor não formule e não responda direta e explicitamente essas questões, elas formam o tecido das reflexões que despertam neste leitor, tamanho o entrelaçamento desses aspectos com a pergunta que ele apresenta em sua Introdução: "o que a Antropologia descobriu que fez com que o Cristianismo não fosse mais defensável?".

Larsen, que é professor junto ao Departamento de Teologia e Estudos Bíblicos no Wheaton College em Illinois, Fellow tanto da Royal Historical Society quanto da Royal Anthropological Society e foi Visiting Fellow no Trinity College em Cambridge e no All Souls College em Oxford durante a pesquisa que deu origem a este livro, viu-se motivado por trechos e comentários que, a princípio, indicavam a força da nascente antropologia vitoriana em desmontar a crença no cristianismo e, posteriormente, justificavam a rejeição de um duplo pertencimento, isto é, a impossibilidade de ser cristão e antropólogo ao mesmo tempo. Sua pesquisa documental com seis importantes personagens da antropologia britânica - Edward B. Tylor, James G. Frazer, Edward E. Evans-Pritchard, Mary Douglas e o casal Edith e Victor Turner - cobre todo o espectro temporal da antropologia como disciplina moderna, considerando que Tylor é o primeiro professor de uma cadeira de Antropologia em Oxford e Edith Turner está atuante nos Estados Unidos no momento de escrita do livro.

Por mais que alguns dos antropólogos discutidos no livro nunca tenham escondido ou negado suas posições a respeito do cristianismo e da religião de maneira mais ampla, é importante atentar para o fato de que o autor traz novos dados primários, isto é, não se trata apenas de uma compilação de informações já disponíveis. Trabalhando com os arquivos pessoais e institucionais de cada um desses autores, Larsen é capaz de nos mostrar as tensões que afloravam nos respectivos contextos entre os pesquisadores e outros membros antropólogos ou com suas famílias e amigos.

Organizado em cinco capítulos - um para cada autor, sendo o casal Turner tratado em conjunto -, o livro possui muitos méritos por combinar diversos aspectos ao redor de um tema bastante preciso. No entanto, ele pode decepcionar aqueles que esperam encontrar uma metodologia rigorosa nos termos da história intelectual ou na de trajetórias e posicionamentos no campo intelectual. Certamente se trata de um livro para iniciados, na medida em que o conhecimento tanto do contexto quanto das obras dos autores é uma premissa da qual parte o texto, ainda que Larsen faça questão de justificar a sua escolha por esses personagens específicos em vez de outros tantos que poderiam compor a linha temporal da disciplina. Foi decisivo para sua seleção o fato de que todos foram grandes nomes da antropologia, sendo os dois primeiros considerados "pais fundadores" em Oxford e Cambridge; Evans-Pritchard é por muitos reputado como o antropólogo par excellence, sendo seguido pela Dame Douglas, a primeira mulher na disciplina a receber o título real, e terminando com os Turner, cujo nome dá peso a um prêmio de escrita etnográfica.

É preciso também chamar atenção para o papel que o catolicismo possui no livro. Como uma minoria religiosa no contexto britânico, foi desde o final do século 
XIX associado com o lado mágico daquilo que entendemos como religião - considerando sua ênfase nos sacramentos. Assim, Tylor, cuja formação foi Quaker, iniciou seus trabalhos fazendo uma crítica ao catolicismo a partir de sua formação religiosa até generalizar a crítica a ponto de abarcar todo o cristianismo e deixar de ser, ele mesmo, religioso. É essa postura inicial de alguém que, pesquisando lugares exóticos e distantes e entrando em contato - ainda que não de maneira presencial e etnográfica - com outras culturas e crenças, está na raiz daquilo que comumente se entende como um processo de secularização do pensamento social em gestação e desenvolvimento. Esse processo ganharia ainda mais força com Frazer que, seguindo os passos de Tylor, também apresenta sua grande obra - O Ramo de Ouro, cuja seção "O Deus Assassinado" (The Slain God) dá título ao livro - como uma tentativa de desmontar o cristianismo por meio da comparação com outras práticas bárbaras. Frazer, como Larsen nos faz entender, estava no seio de uma família cristã e necessitou por muitas vezes disfarçar mesmo para seus parentes mais próximos o seu desconforto com a religião. É certamente sintomático da postura de Larsen que, ao final deste capítulo, tenhamos a impressão de que Frazer era o intolerante e irracional.

Porém, a grande virada do livro ocorre no terceiro capítulo, com Evans-Pritchard. Não sendo particularmente religioso no início, Evans-Pritchard converte-se ao catolicismo aproximadamente no meio de sua careira. Sua reflexão sobre o dissenso entre os antropólogos e a religião já é bastante conhecida em sua Aquinas Lecture (uma conferência católica para a qual foi convidado e que foi traduzida aqui na revista Religião $\mathcal{B}$ Sociedade em 1986). Muito se discute sobre o fato dele se autodenominar um "mau católico" e o quanto isso seria uma maneira de entender que, no fundo, ele não era católico de maneira alguma. Entretanto, o livro deixa claro que essa autodescrição de Evans-Pritchard se devia a todos os pecados e faltas que ele já tinha cometido e dos quais não era capaz de se perdoar - uma delas, e bastante terrível, a culpa que ele carregava pelas mortes de civis inocentes ao comandar um batalhão durante a Primeira Grande Guerra. A relação entre a produção propriamente antropológica de Evans-Pritchard e o seu comprometimento católico parece estar, segundo Larsen, nos trabalhos pouco lidos no Brasil, sobretudo em Nuer Religion (:107-115).

Se Tylor foi da religião para a sua recusa e Frazer consolidou essa dimensão, com Evans-Pritchard vimos a transição contrária, que irá se consolidar com Mary Douglas, a Dame sempre católica. Criada por freiras, ela mesma faz questão de reforçar a importância e centralidade do catolicismo em sua visão de mundo e ao moldar suas teorias, a ponto de intitular sua fala ao receber um prêmio de intelectual católica de "Um sentimento pela Hierarquia", entendida como a Santa Igreja e também como a importância da totalidade socialmente hierarquizada que ela tanto analisou. Conta-nos Larsen que o mais famoso livro de Douglas, Pureza e Perigo, é resultante de um evento que realçou as restrições alimentares de três professores de Oxford após o seminário de sexta-feira do departamento de antropologia. Ao chegarem no pub e serem confrontados com a oferta de carne de porco, um deles (Franz Steiner) teria 
respondido: "Eu nunca como porco, sou judeu"; um segundo (M. N. Srinivas): "Eu nunca como carne, sou Hindu"; e Douglas teria dito: "Nunca como carne às sextas-feiras, sou católica" (:120).

Embora Larsen mencione a ideia de "ring composition" de Douglas em sua conclusão, segundo a qual é no centro que está o mais importante (isto é, no capítulo 3, sobre Evans-Pritchard), creio que é possível fechar o círculo com esses quatro capítulos e observar o último como um caso singular e de grande relevância para as discussões contemporâneas no Brasil. Durante seu início de carreira, Turner foi um dos mais celebrados membros da chamada Escola de Manchester e era, assim como muitos dos seus colegas, não apenas marxista como também membro do Partido Comunista (Edith Turner relata para o autor que muitos eram também "ateístas de esquerda"). O choque de todos os membros do departamento foi tão grande quando ele e sua esposa se converteram ao catolicismo após sua experiência de campo que ele sentiu que não era mais possível continuar trabalhando ali. Dentre os documentos recuperados na pesquisa, Larsen nos traz uma carta de Turner para Gluckman, que foi seu supervisor, datada após sua conversão e decorrente ruptura intelectual com o departamento em Manchester. Sua explicação começa com a frase: "Eu me tornei um teísta por não conseguir ver bases racionais para um ato de fé na não existência de Deus"1 (:185-186). Porém, o que nos permite uma reflexão ainda mais importante é que o casal Turner foi afetado pela sua experiência de campo. A transformação operada no encontro com os Ndembu é que foi crucial nessa abertura para o transcendente: "Eu não fiquei imune aos poderes simbólicos que invoquei na pesquisa de campo. Depois de muitos anos como agnóstico e materialista monista, Eu aprendi com os Ndembu que ritual e simbolismo não são meros epifenômenos ou disfarces para processos sociais e psicológicos mais profundos, mas possuem valor ontológico..." (:184).

Ao voltarem para a Inglaterra, os Turner resolveram frequentar diversas igrejas até que se perderam um domingo no caminho para uma delas, e ambos sentiram uma mão em seus ombros direcionando-os para um determinado caminho. E ali estavam eles, no meio de pessoas se encaminhando para a Igreja Católica. Em um texto (Ritual, Tribal and Catholic) publicado em um periódico católico, Victor Turner afirmaria sobre uma missa: "Na performance dele eu senti o mesmo contato intenso com a condição humana pintada de transcendência que eu experimentara na África Central quando participei de rituais conduzidos por dedicados especialistas rituais"3 (:183).

O que Turner nos traz avant la lettre é, então, o impacto da experiência (um conceito que ele utilizou bastante) de campo e a intensidade com que ela pode afetar a vida do pesquisador. Afetar não apenas a vida pessoal, mas também o fluxo que isso traz para os conceitos e noções antropológicas: do Evangelho lido como dramas sociais, passando pelas performances e rituais das missas, à proposta de uma antropologia da peregrinação - que é fruto das peregrinações que o casal fazia como crentes! - e chegando ainda ao seu grande livro $O$ processo ritual, em que a experiên- 
cia de liminaridade foi conceituada no doloroso período em que se encontrava fora de Manchester e não ainda no novo posto, nos Estados Unidos. Se Douglas falou de hierarquia e de totalidade, podemos ver neste outro católico a preocupação com a communitas, aquele momento em que estão todos despidos dos seus papéis sociais e se encontram reunidos como iguais por intensos laços de afeto.

Ao terminarmos de ler um livro como este, nossa sensação é de que experimentamos uma renovada observação por algo que já sabíamos, ou que achávamos que sabíamos: a importância e o impacto da religião - e, ainda mais, de um cristianismo católico - não apenas na história da antropologia britânica como objeto, mas, sobretudo, como um elemento capaz de influenciar teorias e conceitos. Ao fim desta peregrinação e ao olhar para as obras destes autores, temos a sensação de que está tudo um pouco mais sagrado.

\section{Notas}

1 "I became a theist because I could see no rational grounds for making an act of faith in the nonexistence of God" (:185-186).

2 "I have not been immune to the symbolic powers I have invoked in the field investigation. After many years as an agnostic and monistic materialist I learned from the Ndembu that ritual and its symbolism are not merely epiphenomena or disguises of deeper social and psychological processes, but have ontological value..." (:184).

3 "I felt in the texture of his performance something of the same deep contact with the human condition tinged with transcendence that I had experienced in Central Africa when I attended rituals presided over by dedicated ritual specialists" (:183).

Eduardo Dullo (edudullo@gmail.com)

Bolsista FAPESP de pós-doutorado junto ao Departamento de Antropologia da USP, pesquisador associado ao CEBRAP e visiting scholar junto ao Departamento de Antropologia Social da Universidade de Cambridge. 